\title{
OsWRKY03, a rice transcriptional activator that functions in defense sig- naling pathway upstream of OsNPR1
}

\author{
Xiao Qiang LIU ${ }^{1,2}$, Xian Quan BAI ${ }^{1,2}$, Qian QIAN ${ }^{3}$, Xiu Jie WANG ${ }^{1}$, Ming Sheng CHEN $^{1}$, Cheng Cai CHU ${ }^{1, *}$ \\ ${ }^{1}$ National Key Laboratory of Plant Genomics, Institute of Genetics and Developmental Biology, Chinese Academy of Sciences, \\ Beijing 100101, China \\ ${ }^{2}$ Graduate School of the Chinese Academy of Sciences, Yuquan Road, Beijing 100039, China \\ ${ }^{3}$ China National Rice Research Institute, Chinese Academy of Agricultural Sciences, Hangzhou 310006, China
}

\begin{abstract}
WRKY family proteins are a class of plant specific transcription factors that involve in many stress response pathways. It has been shown that one Arabidopsis WRKY protein, AtWRKY29/22, is activated by MAP kinase signaling cascade and confers resistance to both bacterial and fungal pathogens. However, little is known about the biological roles of WRKY proteins in rice. In this study, we investigated the expression patterns of rice AtWRKY29/22 homolog, OsWRKY03, under different conditions, and also its possible role involved in plant defense. Our results showed that OsWRKY03 was up-regulated by several defense signaling molecules or different treatments. Further analysis revealed that the expression of $O s W R K Y 03$ was light dependent. Transcriptional activation activity of OsWRKY03 was also demonstrated by yeast functional assay. Transient expression of OsWRKY03-GFP fusion protein in onion epidermis cells showed that OsWRKY03 was a nuclear localized protein. OsNPR1 as well as several other pathogenesis-related genes, such as $O s P R 1 b$, phenylalanine ammonia-lyase $(Z B 8)$ and peroxidase (POX22.3), were induced in OsWRKY03-overexpressing transgenic plants. These results indicated that OsWRKY03 is located upstream of OsNPR1 as a transcriptional activator in salicylic acid (SA)-dependent or jasmonic acid (JA)-dependent defense signaling cascades.
\end{abstract}

Keywords: defense response, OsWRKY03, transcription factor, rice.

\section{INTRODUCTION}

Plants have developed a number of inducible defense systems against pathogen attacks. It was shown that plants are capable of differentially activating distinct defense pathways depending on the type of pathogen encountered. Plant signaling molecules, such as salicylic acid (SA), jasmonic acid (JA) and ethylene, play important roles in defense signaling networks [1-3].

\footnotetext{
*Correspondence: Cheng Cai CHU

Tel/Fax: +86-10-64877570;

E-mail: ccchu@genetics.ac.cn

Abbreviations: ACC (1-aminocyclo-propane-1-carboxylic acid); BTH (benzo-1,2,3-thiadiazole-7-carbothioic acid S-methyl ester); CHS (chalcone synthase); GP (glutathione peroxidase); GST (glutathione Stransferase); ISR (induced systemic resistance); MeJA (methyl jasmonate); ORF (open reading frame); PAL (phenylalanine ammonia lyase); PR (pathogenesis-related); SA (salicylic acid); JA (jasmonic acid); SAR (systemic acquired resistance); X-gal (5-bromo-4-chloro-3indolyl- $\beta$-D-galactopyranoside).
}

Systemic acquired resistance (SAR) is a classic inducible defense response activated by a necrotizing pathogen [4]. Typical SAR results in an increment of endogenous SA and transcriptional activation of pathogenesis-related $(P R)$ genes (e.g., $P R 1, P R 2, P R 5)$ [5]. It finally leads to an enhanced resistance to a broad spectrum of pathogens in distant and uninfected plant parts [6-9]. Inhibition of SA accumulation can effectively block the activation of SAdependent defense response [10]. Exogenous application of SA or its synthetic functional analog BTH can activate $P R$-gene expression and enhance host resistance to pathogens [11]. It has been shown that SA is an essential signal for SAR across a wide range of plant species although the mechanism of SA induced SAR might differ from one to another [12-14].

In addition to SA, other signaling molecules, such as JA and ethylene, are also able to regulate various plant defense responses. JA- and ethylene-mediated signaling pathways are distinct from the classic SA-mediated SAR pathways [15]. For example, induced systemic resistance (ISR), 
which is triggered by nonpathogenic root-colonizing bacteria, is JA and ethylene dependent $[16,17]$ and is independent of SA and $P R$-gene activation $[18,19]$. The JA response mutant jarl and the ethylene response mutant etrl lose ISR upon treatment with Pseudomonas fluorescens WCS417r, but remain normal level of pathogen-induced SAR $[20,21]$, indicating that JA and ethylene responses are critical for the ISR-signaling pathway [22, 23]. Analysis of signaling molecules involved in rhizobacteria-madiated ISR suggests that ISR might be associated with another pathogen-induced jasmonate and ethylene defense response, in which a subset of $P R$ genes, such as $P R 3$, $P R 4$, and $P R 12$, were co-regulated by jasmonate and ethylene $[24,25]$. However, there is no increment in transcript abundance of jasmonate-inducible gene AtVSP, ethylene-inducible gene $H E L$, and jasmonate- and ethyleneinducible plant defense gene $P D F 1.2$ in rhizobacteria-mediated ISR in Arabidopsis [22]. Thus, rhizobacteria-mediated ISR signaling pathway does not coincide with pathogen-induced jasmonate and ethylene response [22].

More than a decade ago, additional components downstream of signaling molecules SA, JA and ethylene were characterized in several mutant plants, such as the jasmonate response mutant jar [26], the ethylene response mutant etr [27] and the SAR regulatory mutant nprl [28]. In a genetic screening for plants failed to express $P R$ genes after SAR induction, nprl mutant was isolated in Arabidopsis [28] and NPR1 gene was cloned [29]. Further results revealed that NPR1 was a key regulator of SA-mediated SAR in Arabidopsis [30-32]. Arabidopsis NPR1/NIM1 gene encodes a novel protein with ankyrin repeats [29], which is essential for NPR1 binding to the TGA basic leucine zipper transcription factors [33]. The interaction between NPR1 and TGA factors facilitates the binding of TGA proteins to the SA-responsive as- 1 or as1 -like promoter elements, and leads to the activation of downstream genes during defense response [34, 35].

The activation of NPR 1 is not only required for the expression of $P R$ genes in SA-dependent SAR, but also for the jasmonate- and ethylene-dependent rhizobacteriamediated ISR [22, 36]. SAR and ISR can be activated simultaneously, leads to synergetic additive protection against plant pathogens, such as $P$. syringae [37]. However, NPR1 is not required for the expression of the $P D F 1.2$ during JA/ethylene-dependent defense responses induced by some necrotrophic pathogens [24, 25]. It has been shown that the SA-inducible NPR 1 -independent pathway also exist $[38,39]$.

Furthermore, NPR1 mediates cross-talk between the SA, JA and ethylene signaling pathways, generating resistance to insects and some necrotrophic pathogens [40]. Therefore, NPR1 is a key regulatory component which locates at the crossroads of multiple defense pathways. The functions of NPR 1 were mainly characterized in Arabidopsis, rice NPR1 was identified just recently [42]. It has been shown that overexpression of $O s N P R I$ gene in rice leads to constitutive activation of defense response and hypersensitivity to light [42]. Transgenic rice overexpressing $O s N P R 1$ gene displayed enhanced resistance to rice bacterial blight pathogen Xanthomonas oryzae pv. Oryzae (Xoo) (Jia Xun FENG, personal communication, unpublished data). These results suggested that rice NPRI gene might have similar function as their Arabidopsis homolog and a disease-resistance pathway similar to Arabidopsis NPR1-mediated signal transduction pathway also exists in rice [41].

Except for the defense inducible gene products immediately downstream of pathogen perception, such as protein kinases, phosphatases and G-proteins, other signal molecules, such as ROS, lipid peroxides, SA, JA, and ethylene, were generated during defense response [43]. Once the earliest defense response starts, enormous biochemical pathways within the responding cells are activated, followed by the induction of a number of defense-related genes, such as $P R s$, phenylalanine ammonia-lyase $(P A L)$, chalcone synthase $(C H S)$, glucanase, chitinase and also those protectant genes, such as glutathione S-transferase $(G S T)$, glutathione peroxidase $(G P)$, peroxidase [4], to activate cell protection mechanisms.

As mentioned above, transcriptional activation of defense-related genes plays a central role in plant defense. Such process requires the expression of related transcription factors. Recently, the plant-specific transcription factors, WRKY family proteins containing highly conserved WRKY domain [44], have been found to be involved in the regulation of plant defense response. It has been shown from a number of plants that $W R K Y$ genes are rapidly induced by pathogens, pathogen elicitors, or SA treatment [45-47]. Arabidopsis WRKY transcriptional factor (AtWRKY52), containing a LRR motif of TIR-NBS-LRR subclass $R$ gene products, has been shown to enhance disease resistance to several strains of Ralstonia solanacearum [48]. It was also demonstrated that some $W R K Y$ genes are necessary for inducible expression of defense-related genes in SAR, such as $P R 1$ in Arabidopsis and $P R 10$ in parsley $[49,50]$. In Arabidopsis, WRKY29 has been identified as an important downstream component of a MAPK pathway that confers resistance to both bacterial and fungal pathogens [51]. Recently, Arabidopsis WRKY70 was also identified as a common regulatory component of SA- and JA- dependent defense response, mediating cross-talk between antagonistic pathways downstream of NPR1 [54]. It has been shown that pathogenand SA-induced WRKY proteins also regulate genes en- 
coding proteins with regulatory functions (e.g. receptor protein kinases and NPR1) [52, 53]. Besides participating plant defense response, WRKY transcription factors also involve in the regulation of several other developmental and physiological processes such as trichome initiation [55], senescence [50], carbohydrate anabolism and secondary metabolism $[56,57]$.

Although several OsWRKY genes have been isolated so far, little is known about their functions in defense signaling pathways in rice. In this work, we demonstrated that one of the WRKY genes, OsWRKY03, functions in JA- or SA-defense signaling pathways by regulating $N P R 1$ and defense-related genes.

\section{MATERIALS AND METHODS}

\section{Analysis of Arabidopsis and rice WRKY genes}

The predicted WRKY family protein sequences of Oryza sativa rice (japonica) and Arabidopsis thaliana were downloaded from TIGR rice databases (http://www.tigr.org/) and TAIR (The Arabidopsis Information Resource) A. thaliana genome annotation database release 5 (http://www.arabidopsis.org/) respectively. WRKY proteins sequences of other species were extracted from NCBI. The phylogenetic tree of WRKY proteins was constructed using MEGA3 [58] with pairwise distance computed and the implementation of neighbour-joining algorithm.

\section{Plant materials and treatments}

Rice (O. sativa L. ssp. Indica cv. Guangluai) seedlings were grown in greenhouse at $28^{\circ} \mathrm{C}$ for 6 weeks until it is ready for different treatments. For hormone treatments, 6 -week-old seedlings were sprayed with 2 mM SA (Sigma), 2 mM BTH (Sigma), 2 mM ACC (Sigma), and $100 \mu \mathrm{M}$ MeJA (Sigma), respectively until liquid dripped off the leaves. Mock plants were treated in the same way with $0.1 \%$ (v/v) ethanol solution in which these compounds were dissolved. Infections with bacterial blight pathogen (Xoo) were performed by the scissors-dip method [59]. The wound treatment was carried out by cutting the rice leaves with clean scissors. The treated leaves were harvested at $0,0.5,2,6,12$ and $48 \mathrm{~h}$ post-treatment, frozen in liquid nitrogen immediately, and stored at $-80^{\circ} \mathrm{C}$ for RNA extraction.

\section{Cloning of OsWRKY03 and other defense marker genes}

Clones of the rice NPR1 homologue (OSNPR1, acc No. AY923983), NB8 (acc No. X87946), OsPR1b (acc No.U89895) and POX22.3 (acc No. AF014467) cDNAs were kindly provided by Prof. Jia Xun FENG (Guangxi University, Guangxi, China). OsWRKY03 full-length ORF was amplified from total RNA extracted from SA-treated rice leaves by RT-PCR using a pair of special primers: 5'-ATG GAG CAC TTC AAC GAC TGG GAC CTG-3' and 5'-CTA TAG CGA GAG CCG TCG CCC CAG CAC-3'. The 1011 bp ORF of OsWRKY03 was cloned into pENTRY TOPO vector (pENTRY Directional TOPO Cloning Kit, Invitrogen) according to the manufacturer's instruction, and was confirmed by following sequencing and the GenBank accession number of OsWRKYO3 is AY676924.

\section{RNA isolation and Northern blot analysis}

Total RNAs were isolated as described by Chomazynski and
Sacchi [60]. For Northern blot analysis, $20 \mu \mathrm{g}$ of total RNAs were denatured and separated on a $1.3 \%$ agarose-formaldehyde gel. Ethidium bromide was included in the loading buffer to confirm equal sample loading. After blotting to positively-charged nylon membranes (Amersham Pharmacia Biotech, UK), RNAs were crosslinked by UV irradiation (GS GENE Linker UV Chamber, BIO-RAD). Prehybridization and hybridization buffer contains $0.33 \mathrm{~mol} / \mathrm{L}$ sodium phosphate buffer ( $\mathrm{pH} 8.3$ ), 7\% Na-dodecyl sulfate (SDS) and $20 \mathrm{mmol} / \mathrm{L}$ EDTA (pH 8.0). $\alpha{ }^{3}{ }^{32} \mathrm{P}-\mathrm{dCTP}$-labelled cDNA probes were used and hybridized at $65^{\circ} \mathrm{C}$ for $16-20 \mathrm{~h}$. After hybridization, the membranes were washed at room temperature in $2 \times \mathrm{SSC}, 0.1 \%$ SDS for $10 \mathrm{~min}$ followed by $15 \mathrm{~min}$ washing with $2 \times \mathrm{SSC}, 0.1 \% \mathrm{SDS}$ at $65^{\circ} \mathrm{C}$ twice. Then, the filters were exposed to Storage Phosphor Screen (Amersham Biosciences, USA) and scanned with Phosphoimager (Molecular Dynamics, USA). For rehybridization, the membranes were stripped off by agitation in boiling $0.1 \%$ SDS and 2 mM EDTA (pH8.0) until the solution was cooled down to room temperature. The membranes were then used for rehybridization as described above. About $300 \mathrm{bp}$ long fragment of 3 '-specific region of OsWRKY03 ORF digested by PstI was used as specific probe.

\section{Subcellular localization of OsWRKY03}

The full-length ORF of OsWRKY03 without the termination codon was amplified by PCR with primers containing SpeI site (underlined): 5'-GAACTAGT ATG GAG CAC TTC AAC GAC TGG GA-3', 5'CAACTAGT TAG CGA GAG CCG TCG CCC CA-3'. After verified by sequencing, the fragment was introduced into the SpeI site of the pCAMBIA1302 vector, creating an in-frame fusion between the $O S W R K Y 03$ cDNA and green fluorescent protein $(G F P)$ gene. The fusion construct (35S:OsWRKY03-GFP) and control (35:GFP) were transformed into onion epidermis cells by particle bombardment using PDS-1000/He (BIO-RAD) [61]. After incubation of transformed onion epidermis cells for $24 \mathrm{~h}$ at $28^{\circ} \mathrm{C}$, GFP was detected by a confocal fluorescence microscopy (Olympus FV5000).

\section{Yeast transcriptional activation assay}

The full-length ORF of OsWRKYO3 was amplified by PCR with a pair of primers containing EcoRI site (underlined): 5'-TCGAATTC ATG GAG CAC TTC AAC GAC TG-3', 5'-TCGAATTC CTA TAG CGA GAG CCG TCG CC-3' After cloned into T-vector and sequenced, the fragment was introduced into the EcoRI site of pGAL4-BD vector (Stratagene) and was in-frame fused with the GAL4 DNA binding-domain to generate the resultant plasmid pGAL4-BD-03. According to the manufacturer's protocol (Stratagene), the plasmids pGAL4-W (positive control: wild-type full-length pGAL4), pGAL4-BD (negative control) and pGAL4BD-03 were transformed into yeast YRG-2 cells. The transformed yeast cells were then analyzed on selective medium plates without His (SD-His) to test the expression of the reporter gene HIS3. The expression of another reporter gene $l a c Z$ was analyzed by detection of $\beta$-galactosidase activity with a solution containing a 5-bromo-4chloro-3-indolyl- $\beta$-D-galactopyranoside (X-gal) substrate on filter paper. All the tests were performed according to the manufacturer's instruction (Stratagene).

\section{Generation of $O S W R K Y 03$-overexpressing transgenic rice}

The full-length ORF of OsWRKYO3 was introduced into the binary vector pGW001 (provided by Prof. Kang CHONG, the Institute of Botany, CAS) under the control of the maize ubiquitin pro- 
moter by LR reaction (Gateway LR Clonase plus Enzyme Mix, Invitrogen) generating the resultant plasmid pG03. The pG03 were introduced into Agrobacterium tumeficiens strain AGL1. For rice transformation, mature seed-derived rice callus $(O$. sativa $\mathrm{L}$. cv. Nipponbare) was used and the Agrobacterium-mediated gene-transfer was described by Hiei et al [62] and the calli were selected under $50 \mathrm{mg} / \mathrm{L}$ of hygromycin. After differentiation, twenty independent lines were obtained and confirmed by PCR and histochemical GUS assay.

\section{RESULTS}

\section{Isolation of $O s W R K Y 03$ cDNA}

Hundreds of $W R K Y$ genes from numerous plant spe-

A

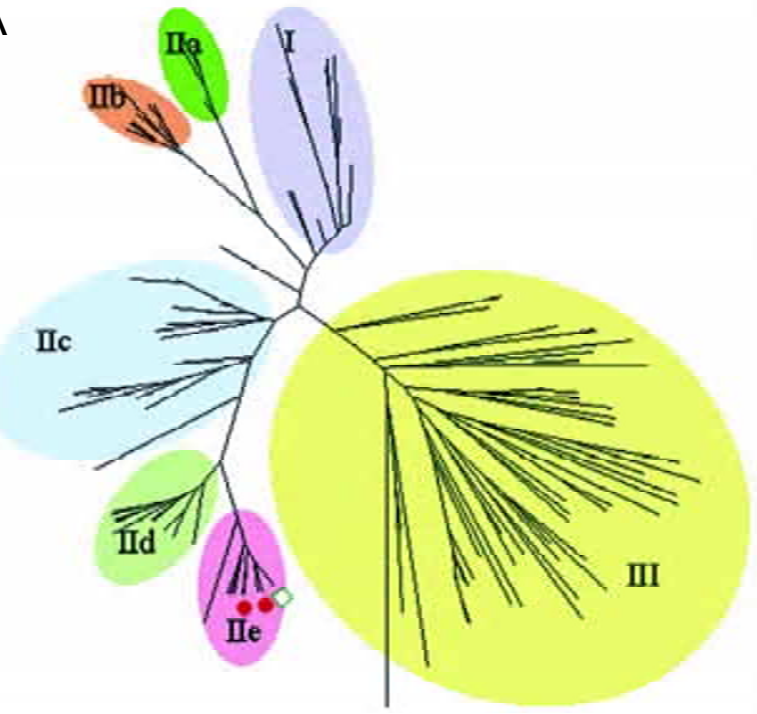

B

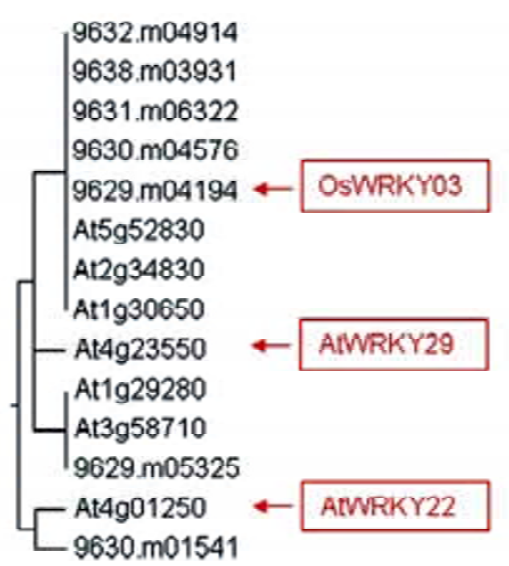

Fig. 1 The phylogenetic tree of WRKY family proteins (A) and partial subtree of the subgroup IIe (B). The phylogenetic tree was constructed using 185 WRKY proteins from rice, Arabidopsis, parsley and tobacco (A). The locations of OsWRKY03 and its Arabidopsis homologs (AtWRKY29 and AtWRKY22) on the phylogenetic tree were marked with blank square and black dots, respectively (A).

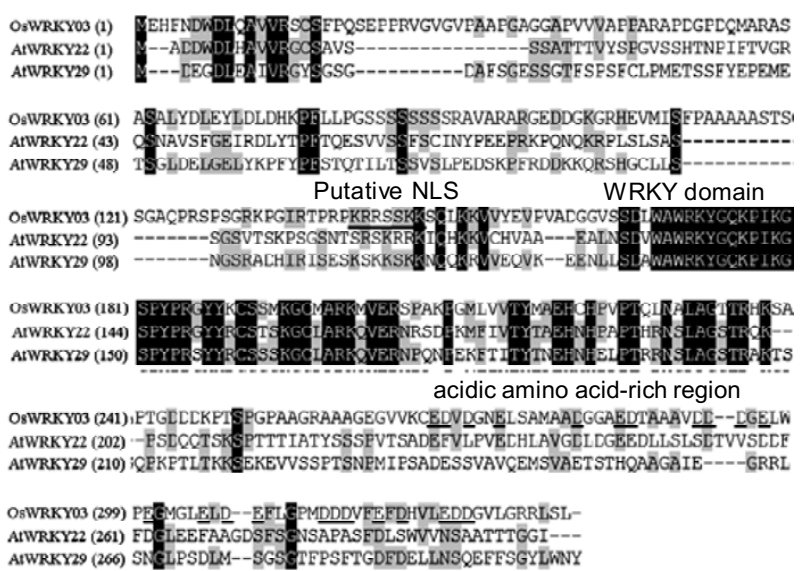

Fig. 2 Alignment of OsWRKY03 with related WRKY proteins from Arabidopsis. The deduced amino acid sequence of OsWRKY03 was aligned with AtWRKY22 (NM_116355) and AtWRKY29 (NM_118486) using Vector NTI with default parameters. Black and gray shadings indicate conserved amino acid residues. Predicted domains are indicated above the sequences. The acidic residues " $E$ " and " $D$ " and putative NLS were underlined.

cies are available in public databases when both of the Arabidopsis and rice genome sequencing projects were completed [63, 64]. To better understand OsWRKY gene family, a phylogenetic tree of 185 WRKY proteins, including 72 from Arabidopsis, 105 from rice and 7 from other species was constructed (Fig. 1A). Based on the predicted Open Reading Frames (ORFs), ten OsWRKY genes were isolated by RT-PCR from the SA-treated rice seedlings. One of them, OsWRKY03, is the closest homolog of AtWRKY29 in the phylogenetic analysis (Fig. 1B). Since AtWRKY29 was identified as an important downstream component of MAPK pathway involved in resistance to both bacterial and fungal pathogens [51], we wanted to investigate whether OsWRKYO3 also plays important roles in rice defense response. The OsWRKYO3 was predicted to encode a 336-amino acid protein that contains a single WRKY domain and a zinc finger-like motif $\left(\mathrm{C}_{2} \mathrm{H}_{2}\right)$ at its Cterminus. OsWRKY03 can be categorized into group IIe of the WRKY superfamily [44] (Fig. 2). OsWRKY03 has a putative basic nuclear localization signals at its $\mathrm{NH}_{2}$ terminus, and an acidic amino acid-rich region at its $\mathrm{C}$ terminus, which may have transcriptional activation activity (Fig. 2). Alignment of the protein sequences of OsWRKY03, AtWRKY29 and AtWRKY22 revealed that the WRKY domains were highly conserved, whereas the rest amino acid sequences are rather diverse (Fig. 2).

\section{Expression patterns of $O S W R K Y 03$ under different treatments}

Plant defense response is regulated by multiple signal 
A
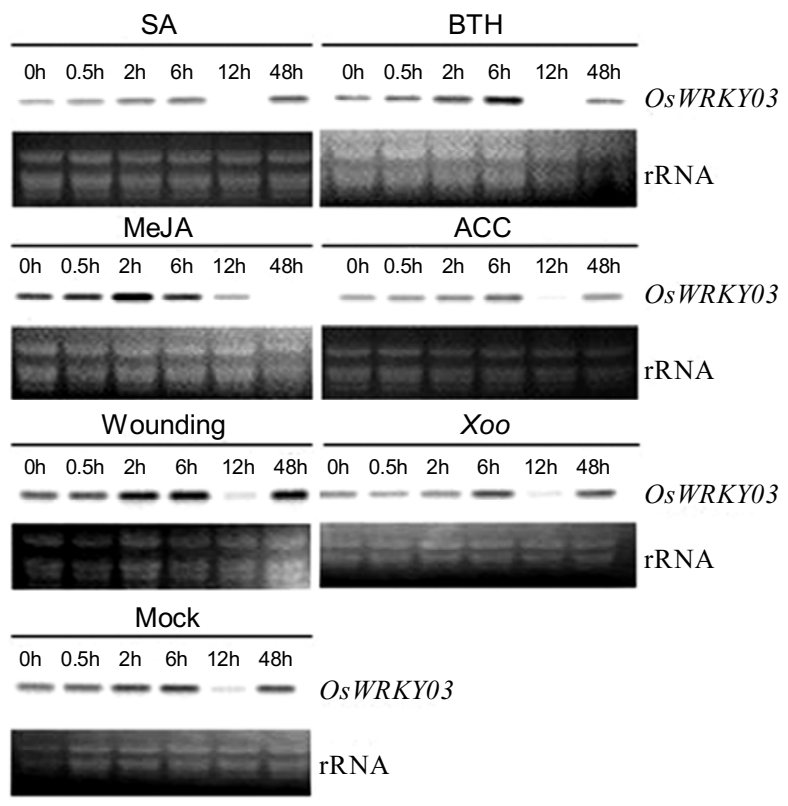

B

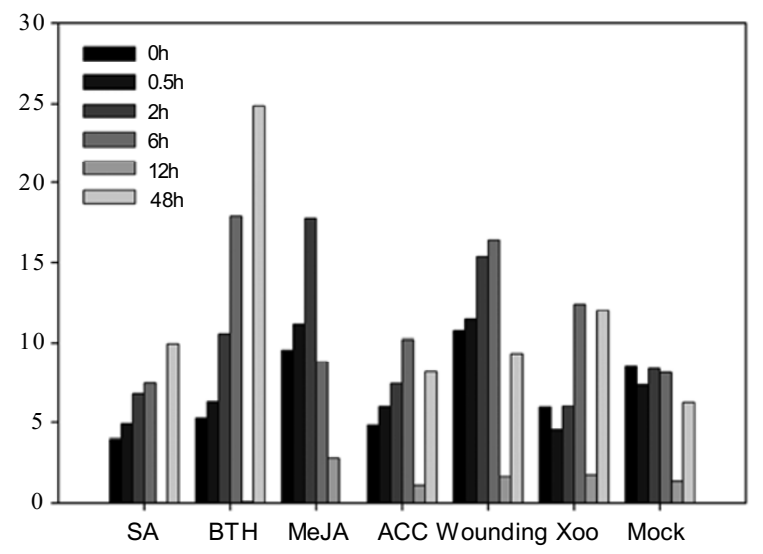

Fig. 3 Expression profiles of $O s W R K Y 03$ transcripts in rice. Expression patterns of $O s W R K Y 03$ in rice seedlings treated with $2 \mathrm{mM} \mathrm{SA}$, $2 \mathrm{mM}$ BTH, $100 \mu \mathrm{M}$ MeJA, $2 \mathrm{mM}$ ACC, rice bacterial blight pathogen $(X o o)$, wounding respectively, and mock control was included (A). About $20 \mu \mathrm{g}$ of total RNA was loaded each lane, equal loading was monitored by ethidium bromide staining of the gels. The $\left[\alpha-{ }^{32} \mathrm{P}\right]$ dCTP-labeled OsWRKY03 3'-specific cDNA was used for hybridization. The signals were then quantitated and the ratio of OsWRKYO3 band intensities to $28 \mathrm{~S}$ rRNA band intensities represented the relative expression level of the OsWRKY03 gene (B).

transduction pathways, in which SA, JA and ethylene function as key signaling molecules [65]. To study the potential functions of OsWRKY03 in plant defense response, the expression profiles of rice WRKY03 gene under wounding, rice bacterial blight pathogen $(X$. oryzae $p v$.
A

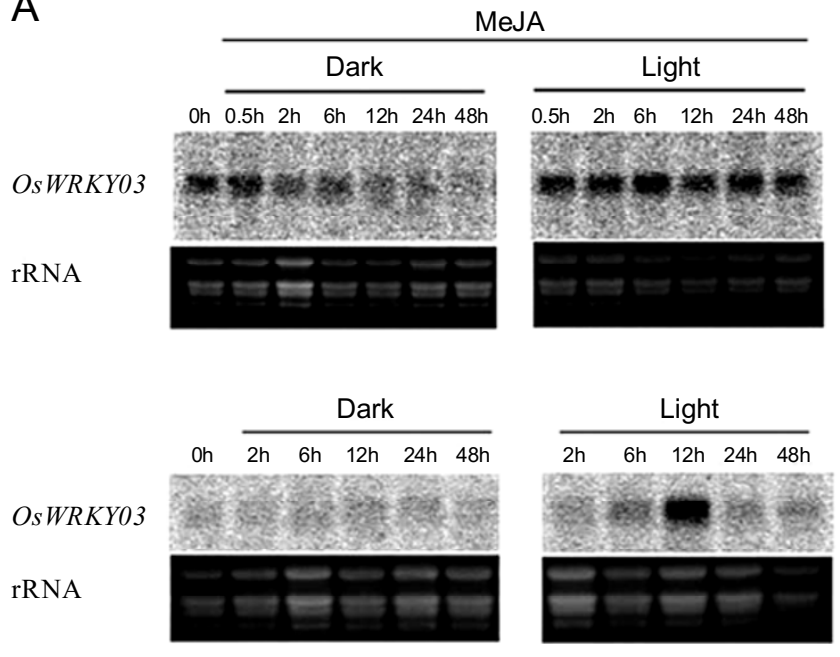

B
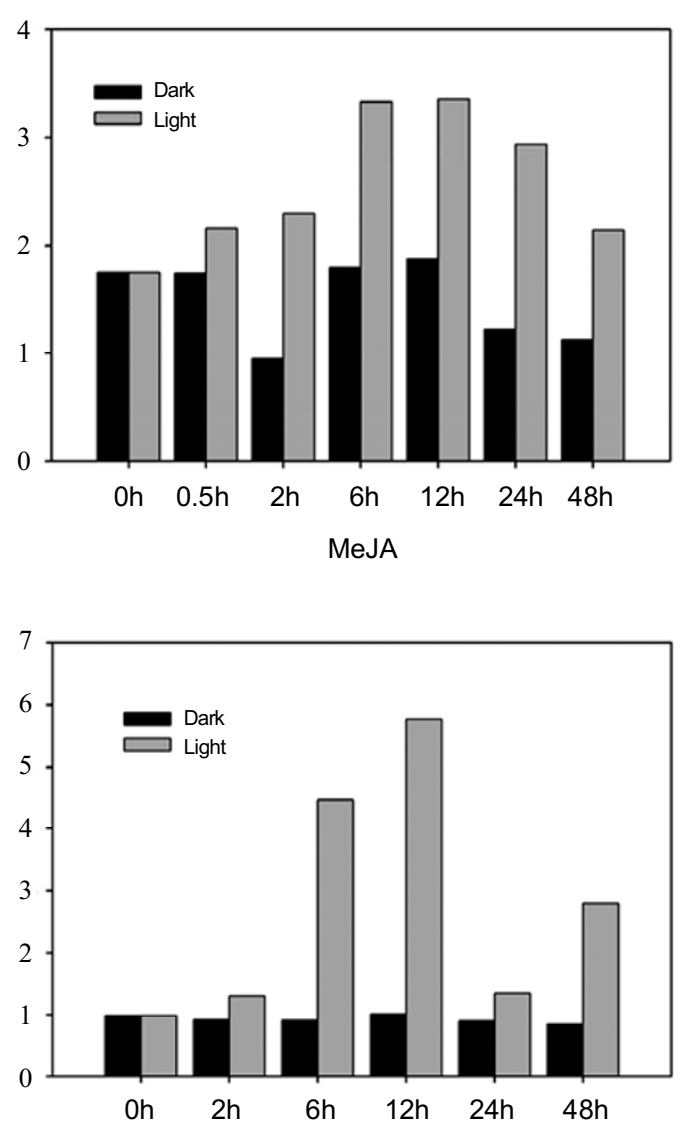

Fig. 4 The expression of OsWRKYO3 in dark and light. (A) Northern analysis of RNA from rice seedling treated with $50 \mu \mathrm{M}$ MeJA and non-treatment in a time-dependent manner, under both continuous light and continuous dark incubation. Equal loading was monitored by ethidium bromide staining of the gels. The $\left[\alpha{ }^{32} \mathrm{P}\right] \mathrm{dCTP}$-labeled OsWRKY03 3'-specific cDNA was used as probe. (B) The signals were quantitated and the ratio of OsWRKY03 band intensities to $28 \mathrm{~S}$ rRNA band intensities represented the relative expression level of the OsWRKY03 gene. 

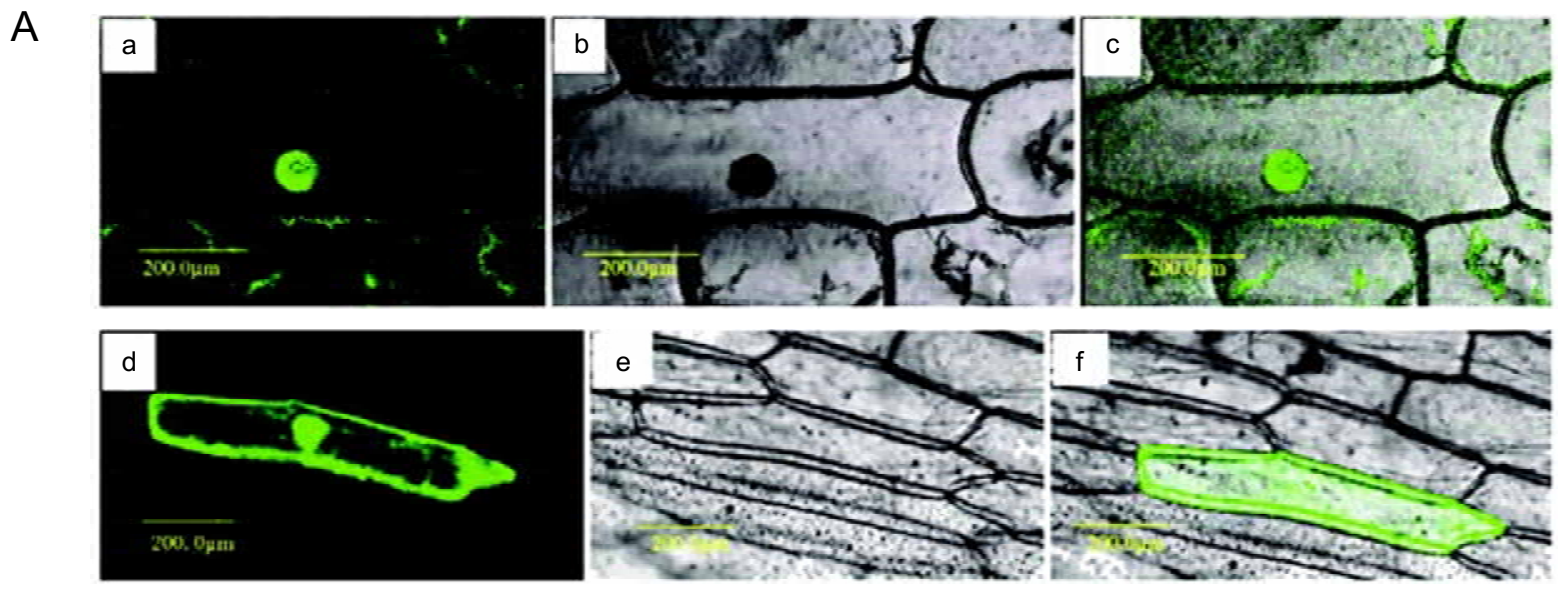

B

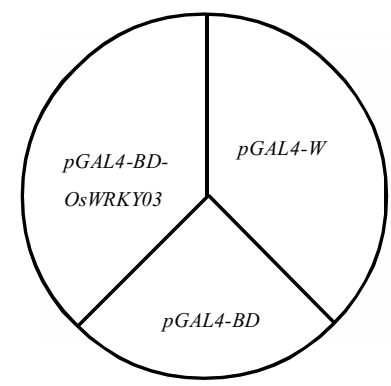

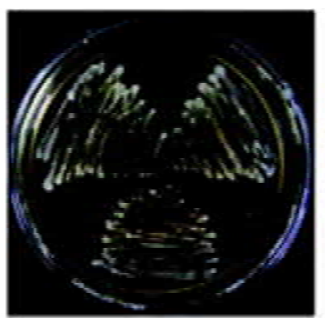

YAPD

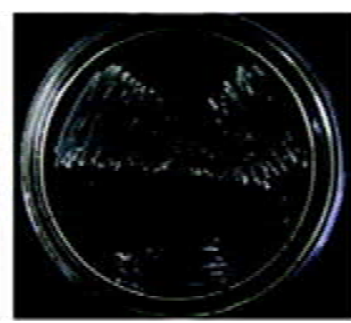

SD-His

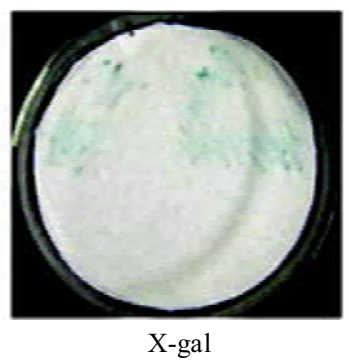

Fig. 5 Nuclear localization of OsWRKY03 and the transactivational activity assay for OsWRKY03 in yeast. (A) The OsWRKY03 protein was localized in nucleus. The photographs were taken in the dark field for green fluorescence ( $\mathrm{a}$ and d), under bright light for the morphology of the cell ( $\mathrm{b}$ and e) and in combination (c and f), respectively for OSWRKY03-GFP plasmid (a, b, and c) and 35:GFP control plasmid (d, e, and f). (B) The OsWRKY03 protein has transactivation activity in yeast. The yeast carrying $p G A L 4-B D$ OsWRKY03 and positive control can grow on the medium without histidine (SD-His) and YAPD, and turn blue on the filter paper with a solution containing an X-gal substrate, while negative control can neither grow on SD-His medium nor turn blue on the filter assay.

Oryzae, Xoo) infection and treatments with different exogenous signal molecules, such as $\mathrm{SA}, \mathrm{BTH}, \mathrm{ACC}$ and MeJA, were investigated. A basal expression of OsWRKY03 was detected in mock-treated plants and is up-regulated in all tested treatments within the first $6 \mathrm{~h}$ after treatment (Fig. 3). However, at $12 \mathrm{~h}$ (even with mock control) the expression level of WRKY03 was significantly decreased, and re-increased at $48 \mathrm{~h}$ (Fig. 3). Since the $12 \mathrm{~h}$ sample was collected from the plants grown in dark, this result suggested that the expression of WRKY03 might be light dependent. To verify this hypothesis, we monitored the abundance of OsWRKYO3 transcripts under both light and dark conditions. After cultivated at $25^{\circ} \mathrm{C}$ and an 18 -h light period per day for two weeks, MeJA was added at $50 \mu \mathrm{M}$ final concentration and the plants in light period were transferred to continuous dark or continuous light. Northern blot analysis showed that OsWRKYO3 expression was upregulated by MeJA only in light, whereas the transcript was reduced in dark even under MeJA treatment (Fig. 4).
Furthermore, plants growing in dark period were transferred to continuous dark and continuous light incubation without any further treatment. The expression of OsWRKYO3 in these plants maintained low level when it was in the dark, but was highly induced when plants were transferred to light (Fig. 4). These results suggested that OsWRKY03 was invovled in plant defense response pathways, in which plant hormones SA, JA and/or ethylene were also participated. We have also demonstrated that the expression of OsWRKYO3 was light-dependent.

\section{OsWRKY03 is nuclear-localized and has transcrip- tional activation activity in yeast}

To determine the subcellular localization of OsWRKY03, the ORF of OsWRKY03 was fused to the GFP in pCAMBIA1302 vector. The construct was introduced into onion epidermal cells by particle bombardment. After incubation for $24 \mathrm{~h}$, GFP fluorescence was detected exclusively in the nucleus, suggesting that OsWRKY03 is a 
nuclear localized protein (Fig. 5A, a-c). In contrast, onion cells transformed with 35S:GFP vector (control) showed fluorescence throughout the cells (Fig. 5A, e-f).

To determine whether OsWRKY03 protein has transcriptional activation activity, a fusion protein containing a GAL4 DNA binding domain (GAL4-BD) and the whole ORF of OSWRKY03 was constructed (pGAL4-BDOsWRKY03). The fusion plasmid pGAL4-BDOsWRKY03, pGAL4-W (positive control) and pGAL4$\mathrm{BD}$ (negative control) were all transformed into yeast strain YRG-2 containing upstream activating sequence (UAS), which could be specifically bound by GAL4 binding domain. All transformants containing pGAL4-W, pGAL4OsWRKY03 and pGAL4-BD grew well on rich medium YAPD (Fig. 5B). The results revealed that yeast transformed by pGAL4-BD-OsWRKY03 can grow on selective medium without histdine (SD-His) and also $\beta$-galactosidase activity can be detected, indicating that the expression of reporter genes (lacZ and HIS3) was activated, whereas neither lacZ nor HIS3 reporter genes could be activated in yeast transformants by negative control (pGAL4-BD) (Fig. 5B). These results indicated that pGAL4-WRKY03 indeed could transactivate the expression of both reporter genes lacZ and HIS3 in the same way as the positive control in yeast (Fig. 5B), suggested that OsWRKY03 was a transcriptional activator.

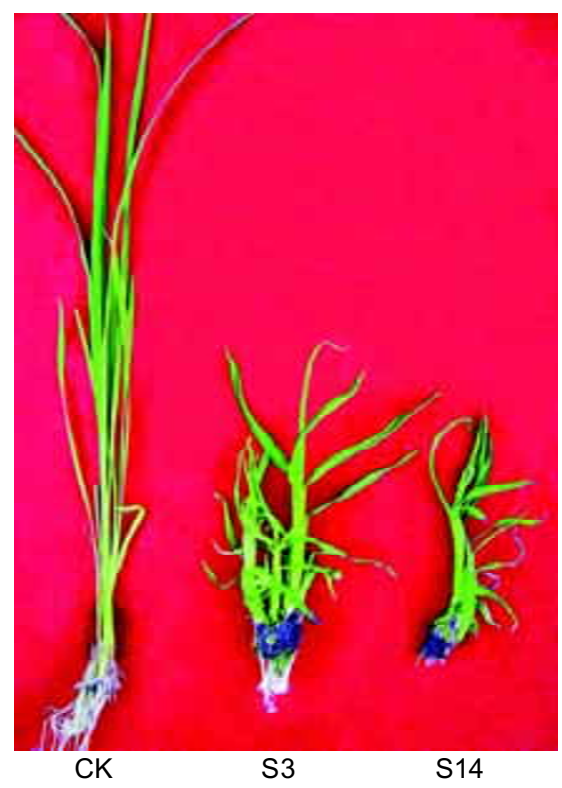

Fig. 6 Phenotypes of $O s W R K Y 03$-overexpressing transgenic rice. The phenotype of the transgenic rice and the control line three months after regeneration. S3 and S14 represent the transgenic lines and CK stands for the plants transformed with empty vector.

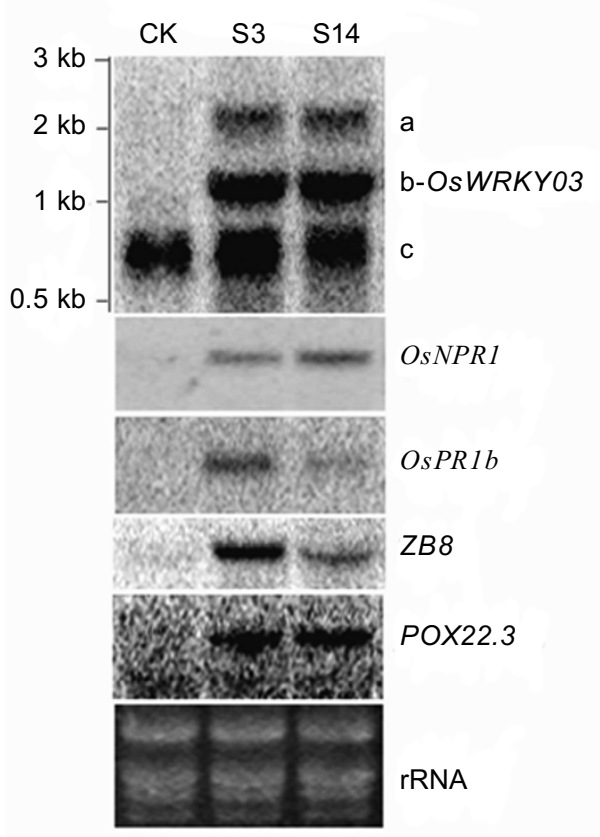

Fig. 7 Expression of OsWRKYO3 and some marker genes in defense pathways in OsWRKY03-overexpressing transgenic rice. Northern blot was hybridized to the $\left[\alpha_{-}{ }^{32} \mathrm{P}\right]$ dCTP-labeled OsWRKYO3 3'specific cDNA probe, three different bands were detected (band $a, b$ and c). According to RNA marker labeled left, band b ( $2 \mathrm{~kb}>$ band $\mathrm{b}$ $>1 \mathrm{~kb})$ is OsWRKYO3 transcript only detected in WRKYO3overexpressing lines. Band a $(3 \mathrm{~kb}>$ band a $>2 \mathrm{~kb})$ and band $\mathrm{c}(1 \mathrm{~kb}$ $>$ band $\mathrm{c}>0.5 \mathrm{~kb}$ ) is likely to be produced by cross hybridization. And the same filter was stripped and rehybridized subsequently with $O s N P R 1, Z B 8$, and $P O X 22.3 \mathrm{cDNA}$ probes. Equal loading was monitored by ethidium bromide staining of the gels. S3 and S14 are two independent transgenic lines and CK represents the plant transformed with empty vector.

\section{Overexpression of $O s W R K Y 03$ gene in transgenic rice}

To elucidate OsWRKY03 function, transgenic rice overexpressing OsWRKYO3 gene was generated, and about 20 independent transgenic lines were obtained. The regenerated transgenic plants containing OsWRKYO3 construct showed overall shoot and root abnormality, such as severe dwarfism, dark green and curly leaves, and root initiation and elongation was greatly reduced (Fig. 6). The plants died eventually after transferring into soil.

To examine OsWRKY03 expression level, Northern blot analysis was carried out with probes derived from Os WRKY03 sequence. The results showed that OsWRKY03 transcripts, with a size of about $1 \mathrm{~kb}$, were substantially elevated in transgenic lines compared with the control (Fig. 7, band b). Besides the expected OsWRKYO3 transcript, two other bands were also detected in our Northern blot hybridization results. Band $\mathrm{c}$ had a size smaller than OsWRKYO3 and was detected in all samples including the 
control lines transformed by empty vector. Band a migrated slower than OsWRKYO3 on the agarose gel and was only present in OsWRKYO3 transgenic lines (Fig. 7). We did not know yet what the band a and band c represent. Because band a could only be detected in transgenic plants, we supposed it probably is another induced WRKY family gene, which has high sequence similarity to OsWRKY03, and is $O s W R K Y 03$-dependent. Because band c could be detected in both the control and transgenic lines, it would be produced by an OsWRKY03 homologues gene whose expression is independent of OsWRKY03. Further experimental verifications are needed to support this hypothesis. RT-PCR was used to further confirm that the band $b$ detected in Northern blot hybridization was indeed the transcript of OsWRKYO3, strong signals were achieved by OsWRKYO3 specific primers in transgenic plants whereas no detectable band was found in control samples (data not shown). These results suggested that the expression of OsWRKYO3 was really elevated in the OsWRKY03 transgenic lines compared to the control.

\section{Overexpression of $O S W R K Y 03$ in rice leads to induced expression of defense-related genes}

To determine whether OsWRKY03 functions in NPR1mediated defense pathways in rice, we investigated the expression level of OsNPR1 in OsWRKYO3 transgenic plants. The results demonstrated that $O S N P R 1$ expression was constitutively induced in transgenic plants but not in control plants (Fig. 7), suggesting that OsWRKY03 functions upstream of NPR1 in defense signal pathway.

The expression of several defense-related genes, such as OSPR $1 b, N B 8$, and $P O X 22.3$ were also analyzed in OsWRKYO3-overexpressing transgenic plants. Pathogenesis-related proteins (PR-proteins) were suggested to inhibit pathogen growth, multiplication and/or spread, and are responsible for the state of SAR in plants [66]. Among known $P R s$ genes, the $P R 1$ class is a dominant group induced by pathogens, and is commonly used as a marker for SAR. In 2000, rice $P R 1$ genes including rice acidic $P R 1$ (OsPR Ia) and rice basic PRI (OsPRIb) were firstly characterized by Ganesh Kumar et al $[67,68]$. To determine whether OsWRKY03 is involved in the regulation of expression of $O S P R 1 b$, we studied the transcripts level of $O s P R 1 b$ in $O s W R K Y 03$-overexpressing transgenic rice and an increased expression of $O S P R I b$ gene was observed in transgenic plants comparing to control, indicating that $O s W R K Y 03$ is located upstream of OsPRIb.

Phenylalanine ammonia-lyase (PAL) catalyzes the first reaction in the biosynthesis of a wide variety of phenylpropanoid natural products including lignin, flavonoid, pigments and phytoalexins, and is the entry point enzyme of the phenylpropanoid and flavonoid pathways. PAL has been proven to be a key enzyme in pathogen defense and stress response [69, 70]. $Z B 8$ is a rice $P A L$ gene and has been shown to be induced under wounding and fungal cell wall elicitor treatment [71]. Peroxidase genes are also a class of protective genes that are induced in plant defense response [5]. One rice peroxidase gene, $P O X 22.3$ has been shown to be predominantly induced upon $X$. oryzae $p v$. Oryzae infection[72]. To determine whether defense-related genes, $Z B 8$ and $P O X 22.3$ genes are regulated by OsWRKY03, we examined their expression levels in OsWRKY03 over-expressing transgenic lines. The results showed that both $Z B 8$ and $P O X 22.3$ genes were induced by OsWRKY03 (Fig. 7).

\section{DISCUSSION}

Transcriptional regulation of plant defensive genes plays a central role in the activation of plant inducible defense response. Therefore, an important step toward understanding the regulation of plant defense systems is to identify regulatory components and establish defense response pathways. In the past years, several families of sequencespecific DNA binding transcription factors involving in the transcriptional regulation of plant defense genes have been identified, including ethylene-responsive element binding factors, myb-like factors, bZIP factors and W-box binding WRKY proteins [72]. Since the first WRKY protein (SPF1) was identified in sweet potato [73], much progress has been made in studying the functions of WRKY family transcriptional factors. However, most researches were conducted in dicots plants, such as Arabidopsis, tomato, tobacco and potato. Although many OsWRKY genes have been isolated from different species and about one hundred WRKY family members have been computationally identified in rice, very limited information about the functions of rice $W R K Y$ genes was available. Considering the importance of rice as a model crop genera and a valuable crop species, elucidation of the functions of WRKY proteins in plant defense response signaling pathways has important significance both in basic research and agricultural application. In this paper we provided evidence that $O s W R K Y 03$, a rice $W R K Y$ gene, functions in JA- or SAdefense signaling pathways by regulating $N P R 1$ and other downstream defense-related genes.

Increased expression was observed for OsWRKYO3 upon treatments of different defense related molecules, suggesting that $O s W R K Y 03$ plays a role in rice defense systems. Interestingly, the expression of OsWRKYO3 reduced significantly to almost undetectable level under all treatments at $12 \mathrm{~h}$ post-treatment and was recovered at post-treatment of $48 \mathrm{~h}$ (Fig. 3). In our experiment, all the treatments were undertaken under the natural daytime light condition. The $12 \mathrm{~h}$ post-treatment was exactly in the midnight, 
whereas all other time points were during daytime. This result suggested that the expression of OsWRKYO3 has a circadian rhythm and is light dependent. This hypothesis has been proved by further experiment (Fig. 4). It has been reported that rice $P R 1 b$ gene is highly induced by JA, protein phosphatase inhibitors catharidin $(\mathrm{CN})$ and endothall (EN) [67] in a light-dependent manner. Furthermore, overexpression of OSNPR1 gene leads the plants to be hypersensitive to light [42]. Because the expressions of $P R 1 b, O S N P R 1$ and their upstream regulator $O s W R K Y 03$ are all correlated with light, we hypothesis that the light-dependent expression patterns of OSPRIb is likely to be caused by expression pattern of OsWRKY03.

Ectopic expression can provide much information for gene function [74]. Identification of downstream target genes of WRKY factors will be crucial for the understanding of their biological functions. Currently, our knowledge of $W R K Y$ genes relies mainly on the strong ectopic expression of WRKY genes in transgenic plants or protoplasts $[46,50,51,54]$. In this work, we used $O S N P R 1$, which is a central regulator of plant defense signaling pathways, and several defense-related genes, such as $O S P R 1 b, N B 8$ and $P O X 22.3$, as markers to monitor the functions of $O s W R K Y 03$ in its overexpressing transgenic rice. Both of the two classes marker genes: OsNPR1 and $O S P R 1 b, N B 8$ and $P O X 22.3$ were induced in $O S W R K Y 03$-overexpressing rice, which suggests that $O s W R K Y 03$ locates upstream of $N P R 1$ and $P R 1$ genes in JA- and/or SA-defense response pathway. But the details about functions of OsWRKY03 in the regulation of disease defense signaling pathway are still unclear. For example, how does OsWRKY03 regulate defense-related genes? Is OsNPR1 a mediator? Which phytohormone, SA or JA or both play a role? What is the regulator upstream of OsWRKY03 and the ones downstream of JA and SA? Is there a MAPK cascades upstream of WRKY03 similar to WRKY29 in Arabidopsis [51]? Discovery and analysis of mutants involved in the pathway would provide us more information.

It has been suggested that disease resistance is associated with fitness costs and that plants have evolved inducible defense mechanism because it is too costly to have defense responses switch on all the time [5, 75]. For instance, overexpression of AtWRKY6, AtWRKY18, $A t W R K Y 53$ or $A t W R K Y 70$ always resulted in small stunted transgenic plants $[50,54,76]$. Our OsWRKY03-overexpressing transgenic rice showed more serious phenotype with stunted growth, loss of apical dominance, curly leaves, and finally died after transferred to greenhouse. This is most likely due to the constitutive expression of $N P R 1$ gene and defense-related genes, such as $P R 1, P A L$ and $P O X 22.3$, which allocate much more plant's resources. From this point of view, the transgenic lines with inducible expression of OsWRKY03 will be much helpful for the further elucidation of its biological function in vivo.

\section{ACKNOWLEDGEMENTS}

This work was kindly supported by grants from Chinese Academy of Sciences (CAS) and Plant Gene Research Center (Beijing), and also the grants from National Key Basic Research Projects from Ministry of Science and Technology of China (Grant Nos. 2002CB111301 and 2002CCA03200).

Received, Apr 20, 2005

Revised, July 29, 2005

Accepted, Aug 5, 2005

\section{REFERENCES}

1 Maleck K, Dietrich RA. Defense on multiple fronts: how do plants cope with diverse enemies? Trends Plant Sci 1999; 4:2159.

2 Glazebrook J. Genes controlling expression of defense responses in Arabidopsis. Curr Opin Plant Biol 1999; 2:280-6.

3 Reymond P, Farmer EE. Jasmonate and salicylate as global signals for defense gene expression. Curr Opin Plant Biol 1998; 1: 404-11.

4 Hammond-Kosack KE, Jones JD. Resistance gene-dependent plant defese responses. Plant Cell 1996; 8:1773-91.

5 Durrant WE, Dong X. Systemic acquired resistance. Annu Rev Phytopathol 2004; 42:185-209.

6 Uknes S, Mauch-Mani B, Moyer M, et al. Acquired resistance in Arabidopsis. Plant Cell 1992; 4:645-56.

7 Ryals JA, Neuenschwander UH, Willits MG, et al. Systemic acquired resistance. Plant Cell 1996; 8:1809-19.

8 Dong X. Genetic dissection of systemic acquired resistance. Curr Opin Plant Biol 2001; 4:309-14.

9 Dempsey DA, Shah J, Klessig DF. Salicylic acid and disease resistance in plants. Crit Rev Plant Sci 1999; 18:547-75.

10 Wildermuth MC, Dewdney J, Wu G, Ausubel FM. Isochorismate synthase is required to synthesize salicylic acid for plant defense. Nature 2001; 414:562-5.

11 Shah J. The salicylic acid loop in plant defense. Curr Opin Plant Biol 2003; 6:365-71.

12 Coquoz J-L, Buchal A, MP H, Méraux J. Arachidonic acid induces local but not systemic synthesis of salicylic acid and confers systemic resistance in potato plants to Phytophthora infestans and Alternaria solani. Phytopathology 1995; 85:1219-24.

13 Silverman P, Seskar M, Kanter D, et al. Salicylic acid in rice (biosynthesis, conjugation, and possible role). Plant Physiol 1995; 108:633-9.

14 Yu D, Liu Y, Fan B, Klessig DF, Chen Z. Is the high basal level of salicylic acid important for disease resistance in potato? Plant Physiol 1997; 115:343-9.

15 Turner JG, Ellis C, Devoto A. The jasmonate signal pathway. Plant Cell 2002; 14 Suppl:S153-S64.

16 Farmer EE, Ryan CA. Octadecanoid precursors of jasmonic acid activate the synthesis of wound-inducible proteinase inhibitors. Plant Cell 1992; 4:129-34. 
17 Penninckx IA, Eggermont K, Terras FR, et al. Pathogen-induced systemic activation of a plant defensin gene in Arabidopsis follows a salicylic acid-independent pathway. Plant Cell 1996; 8: 2309-23.

18 van Loon LC, Bakker PA, Pieterse CM. Systemic resistance induced by rhizosphere bacteria. Annu Rev Phytopathol 1998; 36:453-83.

19 Van Wees SC, Pieterse CM, Trijssenaar A, et al. Differential induction of systemic resistance in Arabidopsis by biocontrol bacteria. Mol Plant Microbe Interact 1997; 10:716-24.

20 Lawton K, Weymann K, Friedrich L, et al. Systemic acquired resistance in Arabidopsis requires salicylic acid but not ethylene. Mol Plant Microbe Interact 1995; 8:863-70.

21 Lawton KA, Friedrich L, Hunt M, et al. Benzothiadiazole induces disease resistance in Arabidopsis by activation of the systemic acquired resistance signal transduction pathway. Plant $\mathrm{J}$ 1996; 10:71-82.

22 Pieterse CM, van Wees SC, van Pelt JA, et al. A novel signaling pathway controlling induced systemic resistance in Arabidopsis. Plant Cell 1998; 10:1571-80.

23 Knoester M, Pieterse CM, Bol JF, Van Loon LC. Systemic resistance in Arabidopsis induced by rhizobacteria requires ethylene-dependent signaling at the site of application. Mol Plant Microbe Interact 1999; 12:720-7.

24 Thomma BPHJ, Eggermont K, Penninckx IAMA, et al. Separate jasmonate-dependent and salicylate-dependent defense-response pathways in Arabidopsis are essential for resistance to distinct microbial pathogens. Proc Natl Acad Sci U S A 1998; 95:1510711.

25 Penninckx IA, Thomma BP, Buchala A, Metraux JP, Broekaert WF. Concomitant activation of jasmonate and ethylene response pathways is required for induction of a plant defensin gene in Arabidopsis. Plant Cell 1998; 10:2103-13.

26 Staswick PE, Su W, Howell SH. Methyl jasmonate inhibition of root growth and induction of a leaf protein are decreased in an Arabidopsis thaliana mutant. Proc Natl Acad Sci U S A 1992; 89:6837-40.

27 Bleecker AB, Estelle MA, Somerville C, Kende H. Insensitivity to ethylene conferred by a dominant mutation in Arabidopsis thaliana. Science 1988; 241:1086-9.

28 Cao H, Bowling SA, Gordon AS, Dong X. Characterization of an Arabidopsis Mutant that is nonresponsive to inducers of systemic acquired resistance. Plant Cell 1994; 6:1583-92.

29 Ryals J, Weymann K, Lawton K, et al. The Arabidopsis NIM1 protein shows homology to the mammalian transcription factor inhibitor I kappa B. Plant Cell 1997; 9:425-39.

30 Delaney TP, Friedrich L, Ryals JA. Arabidopsis signal transduction mutant defective in chemically and biologically induced disease resistance. Proc Natl Acad Sci U S A 1995; 92:6602-6.

31 Glazebrook J, Rogers EE, Ausubel FM. Isolation of Arabidopsis mutants with enhanced disease susceptibility by direct screening. Genetics 1996; 143:973-82.

32 Shah J, Tsui F, Klessig DF. Characterization of a salicylic acidinsensitive mutant (sail) of Arabidopsis thaliana, identified in a selective screen utilizing the SA-inducible expression of the $t m s 2$ gene. Mol Plant Microbe Interact 1997; 10:69-78.

33 Zhou JM, Trifa Y, Silva H, et al. NPR1 differentially interacts with members of the TGA/OBF family of transcription factors that bind an element of the $P R-1$ gene required for induction by salicylic acid. Mol Plant Microbe Interact 2000; 13:191-202.

34 Despres C, DeLong C, Glaze S, Liu E, Fobert PR. The Arabidopsis NPR1/NIM1 protein enhances the DNA binding activity of a subgroup of the TGA family of bZIP transcription factors. Plant Cell 2000; 12:279-90.

35 Lebel E, Heifetz P, Thorne L, et al. Functional analysis of regulatory sequences controlling $P R-1$ gene expression in Arabidopsis. Plant J 1998; 16:223-33.

36 Pieterse CM, Van Wees SC, Hoffland E, Van Pelt JA, Van Loon LC. Systemic resistance in Arabidopsis induced by biocontrol bacteria is independent of salicylic acid accumulation and pathogenesis-related gene expression. Plant Cell 1996; 8:1225-37.

37 van Wees SC, de Swart EA, van Pelt JA, van Loon LC, Pieterse $\mathrm{CM}$. Enhancement of induced disease resistance by simultaneous activation of salicylate- and jasmonate-dependent defense pathways in Arabidopsis thaliana. Proc Natl Acad Sci U S A 2000; 97:8711-6.

38 Clarke JD, Volko SM, Ledford H, Ausubel FM, Dong X. Roles of salicylic acid, jasmonic acid, and ethylene in cpr-induced resistance in Arabidopsis. Plant Cell 2000; 12:2175-90.

39 Shah J, Kachroo P, Klessig DF. The Arabidopsis ssi 1 mutation restores pathogenesis-related gene expression in $n p r l$ plants and renders defensin gene expression salicylic acid dependent. Plant Cell 1999; 11:191-206.

40 Spoel SH, Koornneef A, Claessens SM, et al. NPR1 modulates cross-talk between salicylate- and jasmonate-dependent defense pathways through a novel function in the cytosol. Plant Cell 2003; 15:760-70.

41 Chern MS, Fitzgerald HA, Yadav RC, et al. Evidence for a disease-resistance pathway in rice similar to the NPRI-mediated signaling pathway in Arabidopsis. Plant J 2001; 27:101-13.

42 Chern MS, Fitzgerald H, Canlas P, Ronald P. Over-expression of a rice NPR1 homolog leads to constitutive activation of defense response and hypersensitivity to light. Mol Plant Microbe Interact 2005; 18: 511-20.

43 Staskawicz BJ, Ausubel FM, Baker BJ, Ellis JG, Jones JDG. Molecular genetics of plant disease resistance. Science 1995; 268: 661-7.

44 Eulgem T, Rushton PJ, Robatzek S, Somssich IE. The WRKY superfamily of plant transcription factors. Trends Plant Sci 2000; 5:199-206.

45 Chen $\mathrm{C}$, Chen Z. Isolation and characterization of two pathogenand salicylic acid-induced genes encoding WRKY DNA-binding proteins from tobacco. Plant Mol Biol 2000; 42:387-96.

46 Eulgem T, Rushton PJ, Schmelzer E, Hahlbrock K, Somssich IE. Early nuclear events in plant defense signaling: rapid gene activation by WRKY transcription factors. EMBO J 1999; 18:468999.

47 Hara K, Yagi M, Kusano T, Sano H. Rapid systemic accumulation of transcripts encoding a tobacco WRKY transcription factor upon wounding. Mol Gen Genet 2000; 263:30-7.

48 Deslandes L, Olivier J, Theulieres F, et al. Resistance to Ralstonia solanacearum in Arabidopsis thaliana is conferred by the recessive $R R S 1-R$ gene, a member of a novel family of resistance genes. Proc Natl Acad Sci U S A 2002; 99:2404-9.

49 Maleck K, Levine A, Eulgem T, et al. The transcriptome of Arabidopsis thaliana during systemic acquired resistance. Nat Genet 2000; 26:403-10.

50 Robatzek S, Somssich IE. Targets of AtWRKY6 regulation dur- 
ing plant senescence and pathogen defense. Genes Dev 2002; 16: $1139-49$.

51 Asai T, Tena G, Plotnikova J, et al. MAP kinases signaling cascade in Arabidopsis innate immunity. Nature 2002; 415:977-83.

$52 \mathrm{Du} \mathrm{L}$, Chen Z. Identification of genes encoding receptor-like protein kinases as possible targets of pathogen- and salicylic acid-induced WRKY DNA-binding proteins in Arabidopsis. Plant J 2000; 24:837-47.

$53 \mathrm{Yu}$ D, Chen C, Chen Z. Evidence for an important role of WRKY DNA binding proteins in the regulation of NPR1 gene expression. Plant Cell 2001; 13:1527-40.

54 Li J, Brader G, Palva ET. The WRKY70 transcription factor: a node of convergence for jasmonate-mediated and salicylate-mediated signals in plant defense. Plant Cell 2004; 16:319-31.

55 Johnson CS, Kolevski B, Smyth DR. TRANSPARENT TESTA GLABRA2, a trichome and seed coat development gene of Arabidopsis, encodes a WRKY transcription factor. Plant Cell 2002; 14:1359-75.

56 Sun C, Palmqvist S, Olsson $\mathrm{H}$, et al. A novel WRKY transcription factor, SUSIBA2, participates in sugar signaling in barley by binding to the sugar-responsive elements of the iso1 promoter. Plant Cell 2003; 15:2076-92.

57 Xu YH, Wang JW, Wang S, Wang JY, Chen XY. Characterization of GaWRKY1, a cotton transcription factor that regulates the sesquiterpene synthase gene (+)-delta-cadinene synthase-A. Plant Physiol 2004; 135:507-15.

58 Kumar S, Tamura K, Nei M. MEGA3: integrated software for molecular evolutionary genetics analysis and sequence alignment. Brief Bioinform 2004; 5:150-163.

59 Kauffman HE, Reddy APK, Hsieh SPV, Marca SD. An improved technique for evaluation of resistance of rice varieties to Xanthomonas oryzae. Plant Dis Rep 1973; 57:537-41.

60 Chomczynski P, Sacchi N. Single-step method of RNA isolation by acid guanidinium thiocyanate-phenol-chloroform extraction. Anal Biochem 1987; 162:156-9.

61 Xie C, Zhang JS, Zhou HL, et al. Serine/threonine kinase activity in the putative histidine kinase-like ethylene receptor NTHK1 from tobacco. Plant J 2003; 33:385-93.

62 Hiei Y, Ohta S, Komari T, Kumashiro T. Efficient transformation of rice (Oryza sativa L.) mediated by Agrobacterium and sequence analysis of the boundaries of the T-DNA. Plant J 1994; 6:271-82.

$63 \mathrm{Yu} \mathrm{J}, \mathrm{Hu} \mathrm{S}$, Wang J, et al. A draft sequence of the rice genome (Oryza sativa L. ssp. indica). Science 2002; 296:79-92.
64 Arabidopsis Genome Initiative. Analysis of the genome sequence of the flowering plant Arabidopsis thaliana. Nature 2000; 408: 796-815.

65 Glazebrook J. Genes controlling expression of defense responses in Arabidopsis-2001 status. Curr Opin Plant Biol 2001; 4:3018.

66 Van Loon LC, Van Strien EA. The families of pathogenesisrelated proteins, their activities, and comparative analysis of PR-1 type proteins. Physiol Mol Plant Pathol 1999; 55:85-97.

67 Agrawal GK, Rakwal R, Jwa NS. Rice (Oryza sativa L.) OsPRIb genes is phytohormonally regulated in close interaction with light signals. Biochem Biophys Res Commun 2000; 278:290-8.

68 Agrawal GK, Jwa NS, Rakwal R. A novel rice (Oryza sativa L.) acidic $P R 1$ gene highly responsive to cut, phytohormones, and protein phosphatase inhibitors. Biochem Biophys Res Commun 2000; 274:157-65.

69 Lawton MA, Lamb CJ. Transcriptional activation of plant defense genes by fungal elicitor, wounding, and infection. Mol Cell Biol 1987; 7:335-41.

70 Walters D, Cowley T, Mitchell A. Methyl jasmonate alters polyamine metabolish and induces systemic protection against powdery mildew infection in barley seedlings. J Exp Bot 2002; 369:747-56.

71 Zhu Q, Dabi T, Beeche A, et al. Cloning and properties of a rice gene encoding phenylalanine ammonia-lyase. Plant Mol Biol 1995; 29:535-50.

72 Chittoor JM, Leach JE, White FF. Differential induction of a peroxidase gene family during infection of rice by Xanthomonas oryzae pv. oryzae. Mol Plant Microbe Interact 1997; 10:861-71.

73 Rushton PJ, Somssich IE. Transcriptional control of plant genes responsive to pathogens. Curr Opin Plant Biol 1998; 1:311-5.

74 Ishiguro S, Nakamura K. Characterization of a cDNA encoding a novel DNA-binding protein, SPF1, that recognizes SP8 sequences in the 5' upstream regions of genes coding for sporamin and betaamylase from sweet potato. Mol Gen Genet 1994; 244:563-71.

75 Zhang JZ. Overexpression analysis of plant transcription factors. Curr Opin Plant Biol 2003; 6:430-40.

76 Heil M, Baldwin IT. Fitness costs of induced resistance: emerging experimental support for a slippery concept. Trends Plant Sci 2002; 7:61-7.

77 Chen C, Chen Z. Potentiation of developmentally regulated plant defense response by AtWRKY18, a pathogen-induced Arabidopsis transcription factor. Plant Physiol 2002; 129:70616. 